Tyler D. Mayfield

\title{
Literary Structure and Setting in Ezekiel
}

[Literarische Struktur und literarischer Kontext im Buch Ezechiel.]

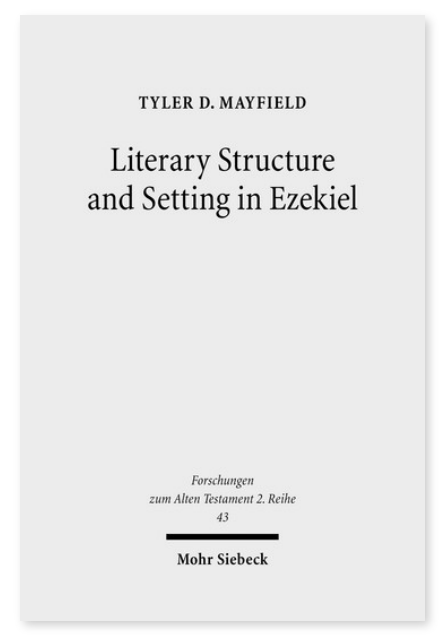

2010. XI, 236 Seiten. FAT II 43

ISBN 978-3-16-151141-7

eBook PDF $69,00 €$

ISBN 978-3-16-150272-9

fadengeheftete Broschur $69,00 €$
Veröffentlicht auf Englisch.

Geschichtlich betrachtet haben formkritische Studien prophetischer Literatur hauptsächlich Geschichtsfragen beantwortet. Jedoch haben Wissenschaftler unlängst begonnen, sich auch mit literarischen Themen als solchen zu befassen. Tyler D. Mayfield beschäftigt sich mit zwei dieser Themen: der literarischen Struktur und dem literarischen Kontext, um Ezechiel als ein wohlüberlegtes literarisches Werk und eine prophetische Komposition mit einer strukturierten Form und einer durchdachten Anordnung von Einheiten lesen zu können. Mayfield liefert eine Diskussion über die Rolle literarischer Kennzeichen in der Struktur und schlägt eine literarische Struktur des Buches vor, die sich auf zwei Muster stützt: das chronologische Muster, das das Buch in 13 kleine Einheiten aufteilt, und das prophetische Wort-Schema. Anschließend plädiert der Autor für ein kontextbezogenes Lesen ausgewählter Passagen Ezechiels und verwendet dazu dessen literarische Struktur, um die literarischen Zusammenhänge zu ergründen.

Tyler D. Mayfield Born 1980; 2009 PhD; since 2012 A.B. Rhodes Professor of Old Testament at Louisville Presbyterian Theological Seminary.

\section{Jetzt bestellen:}

https://mohrsiebeck.com/buch/literary-structure-and-setting-in-ezekiel-9783161511417?no_cache=1 order@mohrsiebeck.com

Telefon: +49 (0)7071-923-17

Telefax: $+49(0) 7071-51104$ 